\title{
Assessment of Mechanical Specific Energy Aimed at Improving Drilling Inefficiencies and Minimize Wellbore Instability
}

\section{Afshin Davarpanah ${ }^{1 *}$, Mojtaba Zarei ${ }^{2}$ and Mehdi-Nassabeh SM $^{3}$}

${ }^{1}$ Department of Petroleum, Science and Research Branch, Islamic Azad University, Tehran, Iran

${ }^{2}$ Department of Chemistry, Islamic Azad University, Shahr Reza, Iran

${ }^{3}$ Department of Petroleum, Islamic Azad University, Omidiye, Iran

\begin{abstract}
Mechanical specific energy is equivalent to the proportion of all the input energy to the bit to output penetration rate. By using this parameter, it can be used to optimize drilling performance, the performance of bit and minimize wellbore instability. By analyzing these parameters, the costs of drilling operations by increasing the rotational speed of drilling equipment, maximizing bit life, and will be reduced. In all parts of the Iran's South Pars field numerous wells have been drilled. But research activity that could be a major step in the evaluation of the mechanical specific energy and reduction of inefficiencies during the drilling operation has not taken place. The purpose of this research using mechanical specific energy is to analyze drilling parameters performance such as bit rotation speed, bit penetration rate in the formation due to rock and fluid properties. According to high costs of hiring drilling rigs and importance of mechanical specific energy for increasing drilling velocity and costs reduction, several researches in many ways for optimizing mechanical specific energy had been studied. However, by using SPSS software in middle formations of one of the phases of Iran's South Pars field statistical studies has been done, which contains formations such as Hith, Surmeh, Neyriz, Dashtak and Kangan.
\end{abstract}

Keywords: Mechanical specific energy; Drilling inefficiencies; Compressive strength; Statistical method; SPSS software

\section{Introduction}

The concept and formula of mechanical specific energy was introduced by Thiel in 1964. Calculation of mechanical specific energy depends on the torque, well diameter, and rotational speed, rate of penetration drill in formation and weight of the bit. Concept of Mechanical specific energy for evaluating the performance of drilling operations and bit performance, as well as are used for the drilling inefficiencies operations. Mechanical specific energy to describe the input amount of energy used in a drilling system that includes mechanical description (weight on bit and torque), for the specified unit (length, area and mass) and required energy to the work (force, time and distance) [1].

Specific energy (SE), required energy was introduced for drilling rock volume, so this concept hasn't been considerably on rock studies as an index [2].

For excavating of a given volume of rock, a minimum energy is required to theoretically calculate that this amount is entirely dependent on the nature and characteristics of the rock. Although, Energy can also be used particularly as an indicator to show changes in lithology and select the correct type of bit according to the drilling operation. Specific energy techniques as a means to help through other methods, such as examining records of previous bits and drilling costs in length unit, is used to select the bit [3-5].

Rotary drilling can be done in two parts: a) the axial force (weight on the bit) work by rotational component (torque). Rotational speed $(\mathrm{N})$, level of bit involvement $(\mathrm{AB})$ and the penetration rate is ROP. So total done work by bit (WOB) by increasing to $\mathrm{Y}$ and forgave lost energy or works that was done on non-drilling operations, it can be written by this correlation:

$$
\mathrm{W}_{\text {Total }}=\mathrm{WOB} \times \mathrm{Y}+2 \times \pi \times \mathrm{N} \times(\mathrm{TQ} / \mathrm{ROP})
$$

Given that $\mathrm{AB} \times \mathrm{Y}$ will be equal to the volume of rocks, so specific energy will be equal to:

$$
\begin{aligned}
& \mathrm{SE}=\frac{\mathrm{WOB}}{\mathrm{AB}}+\frac{2 \times \pi \times \mathrm{N} \times \mathrm{TQ}}{\mathrm{AB} \times \mathrm{ROP}} \\
& \mathrm{SE}=\frac{4 \times \mathrm{WOB} \times \mathrm{ROP}+8 \times \pi \times \mathrm{N} \times \mathrm{TQ}}{\pi \times \mathrm{Db}^{2} \times \mathrm{ROP}}
\end{aligned}
$$

So, that $\mathrm{Db}$ is the bit diameter.

The use of specific energy was done in two contemporary appraisal methods by bit drilling (to determine when to replace the bit) and evaluated after drilling (evaluate of bit performance).

By using above principle description, an equation for calculating mechanical specific energy (MSE) due to the torsional and axial work by bit in removing of rock volume is obtained. So, this equation in atmospheric and hydrostatic conditions according to correlation 1-4 was obtained.

$$
\text { MSE }=\text { efficiency factor } \times\left(\frac{4 \times \mathrm{WOB}}{\pi \times \mathrm{Db}^{2}}+\frac{480 \times \mathrm{N} \times \mathrm{TQ}}{\mathrm{Db}^{2} \times \mathrm{ROP}}\right)
$$

In some cases, productivity factor is considered one. But in some cases, due to bit efficiency in the best performance, is reached to 30- 40 percent, drilling operators considered this coefficient without type of bit and weight on it, 0.35 .

When the mud pump was used in well, correlation 1-5 for obtaining mechanical specific energy is,

"Corresponding author: Afshin Davarpanah, Department of Petroleum, Science and Research Branch, Islamic Azad University, Tehran, Iran, Tel: 989337223427 E-mail: afshindpe@gmail.com

Received November 02, 2016; Accepted November 25, 2016; Published December 02, 2016

Citation: Davarpanah A, Zarei M, Mehdi-Nassabeh SM (2016) Assessment of Mechanical Specific Energy Aimed at Improving Drilling Inefficiencies and Minimize Wellbore Instability. J Pet Environ Biotechnol 7: 309. doi: 10.4172/2157 7463.1000309

Copyright: @ 2016 Davarpanah A, et al. This is an open-access article distributed under the terms of the Creative Commons Attribution License, which permits unrestricted use, distribution, and reproduction in any medium, provided the original author and source are credited. 


$$
\operatorname{MSE}(\mathrm{ksi})=\frac{4 \times \mathrm{WOB}}{\pi \times \mathrm{Db}^{2}}+\frac{480 \times\left(\mathrm{N}+\mathrm{K}_{\mathrm{N}} \times \mathrm{Q}\right) \times\left(\left(\frac{\mathrm{TQ}_{\text {Max }}}{\Delta \mathrm{P}_{\text {Max }}}\right) \times \frac{\mathrm{HP}}{1000}\right)}{\mathrm{Db}^{2} \times \mathrm{ROP}}
$$

\section{Compressive strength}

The compressive strength is equal to the amount of uniaxial compressive stress, when the considered element was completely severed. The amount of compressive strength, usually obtained by pressure testing and experimentally. Pressure testing machine, is used for tensile testing. The difference is that instead of applying a uniaxial compressive load, uniaxial tensile load is applied. In Pressure test, test sample (usually cylindrical) is shorter and fatter. Using the results of stress-strain curve is plotted in Figure 1 [6-8].

\section{Uniaxial compressive strength (UCS)}

Rock strength parameters that reflect the actual energy required to remove the rock. In other words, the highest axial tension that rocks can tolerate. Mechanical specific energy determines the parameters of drilling and energy unit to remove the rock. The distances of Mechanical specific energy with uniaxial compressive strength means the energy of the formation. As a result, the aim of optimizing to minimize the distances between Mechanical specific energy and uniaxial compressive strength. Mechanical specific energy can assess the relative efficiency of drilling operations alone but by compressive strength of rock can be a good scale for drilling.

\section{Working procedure}

In this study, 25/12-inch cross-sectional data from all wells on a platform in one of the phases of the Iran's South Pars field were collected and studied. According to the same rock strength parameters in the same formation, the required amount of energy needed to drill formations in all wells should be similar, otherwise they are not optimum parameters or the bit is not suitable.

In the first part of study, the optimum range for each drilling parameter that increasing drilling velocity and reducing mechanical specific energy that was presented for this region.

In part two, between varieties of statistical methods, SPSS software was used in this research. It should also be noted that the proposed equations are related to the values indicated in the first part. If you use the equations in this area, for parameters outside of this range you should be more careful.

In general, the methods of forecasting engineering problems can be divided into two categories: data analyzing and statistical methods. Data analyzing methods include techniques such as neural networks. Statistical methods are also included types of regression.

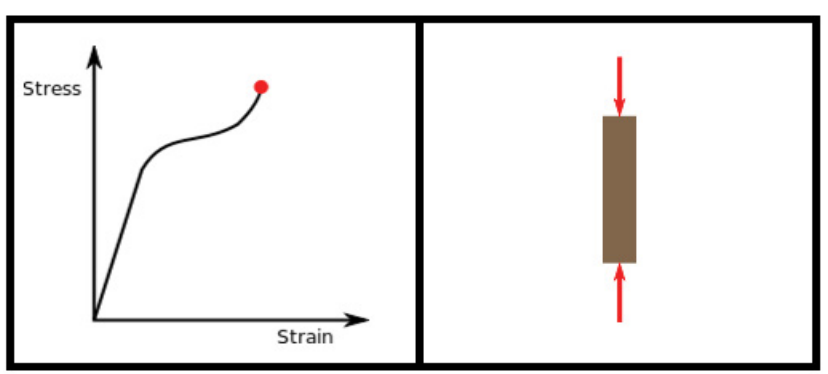

Figure 1: Uniaxial compressive stress and stress-strain curve for a typical engineering.
Statistics is the science of collecting, arranging or organizing, analyzing and interpreting data to determine the validity and generalizability of the results is discussed. Statistical analysis helps researchers to process raw data, extract required information and, if necessary, to generalize the results. If the data volume is large, the use of various methods of statistical analysis will be very tedious and difficult. Today, a variety of statistics software are available, and they can do a variety of statistical analyzes in this research, by using the SPSS software, which is one of the oldest applications in the field of statistical analysis. The word SPSS stands for Statistical Package for Social Science (Software for Social Sciences).

Statistics is divided into two parts: Statistical Parametric and Nonparametric statistics. Statistics parameter split into descriptive and inferential statistics $[9,10]$.

\section{Descriptive statistics}

Descriptive statistics were used to collect, summarize, display and processing of statistical data addresses. In this research, in order to display specification a set of data used, ranges, minimum, maximum, average, standard deviation and coefficient of variation will be provided. The number of samples collected can be evaluated to show importance of relationships extracted from their help. In this context, minimum and maximum values to calculate the ranges that were mentioned.

Average is the easiest and the most important indicator of the data center. Central index is a value that specifies the data center. Researchers can use out of a vast number of variables to compare together. Standard deviation is an important indicator to measure the values of a variable dispersion. If the value of a variable standard deviation divided by the average, the coefficient of variation is a relative index to compare different variables. If the variation coefficient of values is higher it describes greater values of dispersion.

\section{Inferential statistics}

Some methods to analyze observations validate and determine its results. Among these statistical methods we can refer to types of regression. In inferential statistics firstly determined linear relationship between mechanical specific energy with other drilling parameters in both the intercept and without intercept are displayed. Criteria Selection for each of the relations with intercept and without intercept, $R^{2}$ and test is (F Value). The $R^{2}$ (coefficient of determination) shows precision of mechanical specific energy and other drilling parameters. The amount of correlation coefficient shows relationship between parameters. So that:

\section{$\mathrm{R}>0.8$ : high relationship between the two parameters.}

$0.2<\mathrm{R}>0.8$ the relationship between the two parameters. $\mathrm{R}<0.2$ poor relationship between the two parameters.

\section{Linear correlations}

Examine the linear correlation without intercept between mechanical specific energy and other drilling parameters: In Table $1, \mathrm{R}$ (correlation coefficient) which represents the relationship between the parameters and its value is $0.904 . R^{2}$ (Coefficient of determination) indicates the relationship between parameters. Accuracy of correlation is about 0.818 . So by these seven independent parameters, mechanical specific energy can be especially carefully predicted by $81.8 \%$. Or in the other hand, else these seven parameters, other parameters have an $18.2 \%$ impact on mechanical specific energy precision. As a result, in addition to being the determining factor as an accuracy parameter 
Citation: Davarpanah A, Zarei M, Mehdi-Nassabeh SM (2016) Assessment of Mechanical Specific Energy Aimed at Improving Drilling Inefficiencies and Minimize Wellbore Instability. J Pet Environ Biotechnol 7: 309. doi: 10.4172/2157-7463.1000309

it can be an error parameter. The average forecast error, especially mechanical specific energy can fluctuate between 291.6665 (Table 1).

Table 2 average test that named "the analysis of variance test" is called (ANOVA). F is statistical value, significant regression coefficients, and average error of regression to the average actual error of variable, minus the value predicted by the regression equation. The high value of the statistical test showed good relationship between independent and dependent parameters. Sig (significant level) shows the relationship between the independent parameters and dependent parameters. The total errors, medium errors and comparison, are shown in this Table 2. Table 3, B is proposed the coefficients of the independent variables in the formula are. Std. Error shows error of deviation that determines the parameter dispersion. Beta is modified coefficient that the software offer these factors and it can be replaced by B. $\mathbf{t}$ represents the difference between each of the variables significantly associated with the independent variable. Sig, relationship of independent parameter specifies the correlation.

As a result, in Table 4, proposed linear correlation without intercept was presented. All variables are a significant level that was less than 0.1 . This represents a $99 \%$ relationship between the variables that represent the validity of this correlation.

Examine the linear correlation with intercept between mechanical specific energy linear and other drilling parameters: Tables of summarized model, the analysis of variance and linear correlation coefficients with intercept between mechanical specific energy and drilling parameters. Proposed linear correlation with intercept for the studied area, which has a coefficient of determination $(0.62)$ and correlation coefficient is 0.788 .

\section{Nonlinear correlations}

Special nonlinear correlation between mechanical specific energy and the other parameters: The proposed nonlinear correlation 1-6, the simplest case of non-linear correlation with a determination coefficient of 0.775 and relationship coefficient of 0.888 .

MSE $=2.996 \times$ Drilled $^{0.949}-94417.984 \times \mathrm{ROP}^{0.005}+92371 \times \mathrm{N}^{0.003}$ $761.128 \mathrm{WOB}^{-0.12}+10^{-13} \times \mathrm{Q}^{10.482}+1566.384 \Delta \mathrm{P}^{0.112}+0.008 \mathrm{TQ}^{3.525}$

Examine of non-linear correlations between mechanical specific energy with the other parameters when we don't use mud pumps: Nonlinear correlations 1-7 and 1-8 for while don't use mud pumps are proposed that has advantages in comparison to correlation 1-6. Correlation 1-7 with determination coefficient of 0.819 and relationship coefficient of 0.904 . Correlation 1-8 with determination coefficient of 0.813 and relationship coefficient of 0.901 .

$$
\begin{aligned}
\mathrm{MSE} & =\frac{-15066083.746 \times \mathrm{WOB}}{-33331.277 \times \mathrm{Db}^{2}}+\frac{294.374 \times \mathrm{N} \times \mathrm{TQ}}{\mathrm{ROP} \times \mathrm{Db}^{2}} \\
\mathrm{MSE} & =0.662 \times\left(\frac{4 \times \mathrm{WOB}}{\pi \times \mathrm{Db}^{2}}+\frac{480 \times \mathrm{N} \times \mathrm{T}}{\mathrm{ROP} \times \mathrm{Db}^{2}}\right)
\end{aligned}
$$

Examine of non-linear correlations between mechanical specific energy with the other parameters when we used mud pumps: Nonlinear correlations 1-9 and 1-10 for while use mud pumps are

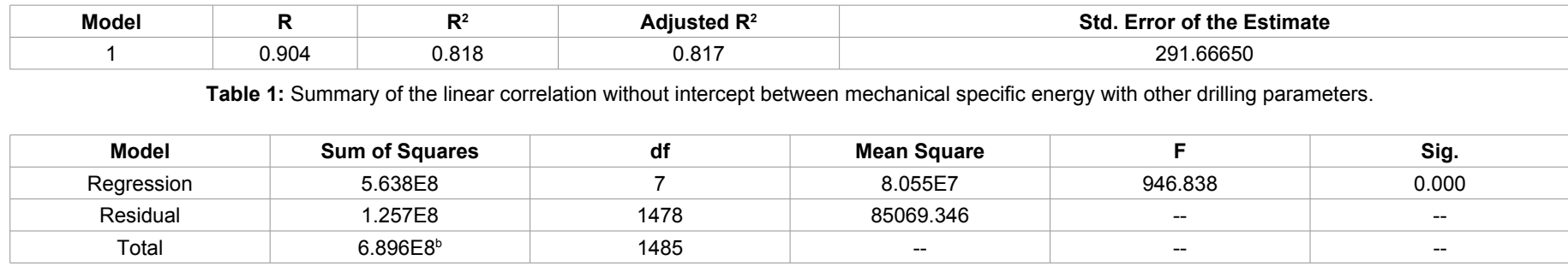

Table 2: The analysis of variance, linear correlation without intercept between mechanical specific energy with other drilling parameters.

\begin{tabular}{|c|c|c|c|c|}
\hline \multirow{2}{*}{ Model } & Unstandardized Coefficients & Standardized Coefficients & \multirow{2}{*}{ Sig. } \\
\cline { 2 - 5 } & B & Std. Error & Beta & -20.351 \\
\hline ROP & -28.120 & 1.382 & -0.594 & 8.083 \\
\hline RPM & 3.287 & 0.407 & 0.510 & 11.201 \\
\hline WOB & 14.083 & 1.257 & 0.420 & -000 \\
\hline Q & -0.511 & 0.059 & -0.651 & .000 \\
\hline TQ & 0.532 & 0.121 & 0.187 & .000 \\
\hline Drilled & 37.890 & 1.812 & 0.876 & .000 \\
\hline
\end{tabular}

\begin{tabular}{|c|c|c|c|c|c|c|}
\hline Sig & $\mathbf{t}$ & parameter & $\mathbf{F}$ & $\mathbf{R 2}$ & $\mathbf{R}$ & Proposed equation \\
\hline 0 & -20.351 & ROP & \multirow{7}{*}{946.838} & \multirow{7}{*}{0.818} & \multirow{7}{*}{0.904} & \multirow{7}{*}{$\begin{array}{c}M S E=-28.120 R O P+3.287 N+14.083 W O B-0.511 Q+0.532 \Delta P-37.89 T Q- \\
2.747 \text { Drilled }\end{array}$} \\
\hline 0 & 8.083 & $N$ & & & & \\
\hline 0 & 11.201 & WOB & & & & \\
\hline 0 & -8.643 & Q & & & & \\
\hline 0 & 4.386 & $\Delta \mathrm{P}$ & & & & \\
\hline 0 & 20.91 & TQ & & & & \\
\hline 0.004 & -2.906 & Drilled & & & & \\
\hline
\end{tabular}

Table 3: Coefficients of the linear correlation without intercept between mechanical specific energy with other drilling parameters.

Table 4: Linear correlation without intercept between mechanical specific energy with other drilling parameters. 
proposed that has advantages in comparison to correlation 1-6. Correlation 1-9 with determination coefficient of 0.837 and relationship coefficient of 0.0914 . Correlation 1-10 with determination coefficient of 0.832 and relationship coefficient of 0.912 .

$$
\begin{gathered}
\mathrm{MSE}=\frac{-127275741.304 \times \mathrm{WOB}}{285060.120 \times \mathrm{Db}^{2}}+\frac{982.325 \times \mathrm{TQ} \times \mathrm{N} \times\left(\frac{\Delta \mathrm{P}}{\Delta \mathrm{P}_{\mathrm{MAX}}}\right)}{\mathrm{ROP} \times \mathrm{Db}^{2}} \\
\mathrm{MSE}=1.899 \times\left(\frac{4 \times \mathrm{WOB}}{1000 \times \pi \times \mathrm{Db}^{2}}+\frac{480 \times \mathrm{TQ} \times \mathrm{N} \times\left(\frac{\Delta \mathrm{P}}{\Delta \mathrm{P}_{\mathrm{M} X}}\right)}{\mathrm{ROP} \times \mathrm{Db}^{2}}\right)
\end{gathered}
$$

Select the most appropriate correlation and determine the most effective parameters on mechanical specific energy

Most favorable linear correlation: Among linear correlation, linear correlation without intercept (Tables 4 and 5) compared to the linear correlation with the intercept (Tables 1-5) is superior because the values of the statistic test, correlation coefficients and coefficients of determination is greater and has the significance level. (Significance level is less than 0.01 of all variables in a linear correlation without intercept represents the correlation between the variables that represent the $99 \%$ level in this regard).

Most favorable nonlinear correlation: Proposed nonlinear correlation between mechanical specific energy with other parameters, when we use mud pump in well (correlations 1-9) has maximum amount of determination coefficient and relationship coefficient that presents high accuracy and more relation with parameters in this correlation than other nonlinear correlation for studied field.

Most favorable correlation to determine the most influential independent parameters on mechanical specific energy: Among the seven proposed correlation, linear correlation without intercept in Table 1 despite a much lower coefficient of determination (slightly) than the proposed non-linear correlations 1-7, 1-9 and 1-10, because linear correlation lead to non-linear correlation and to be considered the most appropriate correlation. Therefore, to identify the most influential independent parameters on mechanical specific energy to linear correlation should be referred without intercept [11-13].

How to determine the most influential independent parameters on mechanical specific energy: In Table 1, which corresponds to the linear correlation without intercept, to compare the significance level parameters, each parameter that is significantly smaller level, would be more effective. In case of equality between the parameter levels, we consider $t$ and whichever is higher absolute of " $t$ ", would be more effective parameter. The most influential independent parameters on the dependent variable (mechanical specific energy) in the studied area in order of torque, the bit penetration rate in the formation, weight on bit, mud flow rate, rotational speed, pressure difference and measure of drilling area. As a result for better and more effective to optimize the mechanical specific energy, it is recommended to optimize effective parameters listed in priority. It should be noted between these parameters, weight on bit, mud flow rate and rotational speed on the rig can be controlled by Drillers. Torque and pressure difference cannot be controlled independently.

On the other hand, torque is directly related to the rotational speed of the rig that can be controlled. (By increasing rotational speed, torque increases). Also, by optimizing the control parameters (weight on bit, mud flow rate and rotational speed) can increase speed of drilling.

Weight on bit was an independent parameter and controllable that due to formation properties and hole-angle would be changed. (If formation was high density, increasing weight on bit due to increasing rotational speed was important. If our purpose increase the hole-angle, weight on bit will be increasing and for decrease hole-angle, reduce weight on bit).

Mud flow rate was a controllable parameter and its effect to create pressure. However, the pressure difference parameter was a parameter that be controlled independently from the rig so by mud flow rate can change it (by increasing the mud flow rate, pressure increases) $[14,15]$.

\section{Summary}

Descriptive statistics, including the number of samples, the highest and lowest dispersion and its causes were investigated. For studied field described investigation of properties reveals standard deviation and coefficient of variation, high changes of parameters such as mechanical specific energy, pressure difference and drilling measure that expresses the dispersion of these variables. Small amounts of these items for the parameters of torque, rotational speed, and mud flow rate, representing less dispersion of this parameter.

Then by inferential statistics we have correlations to predict mechanical specific energy in the studied area was presented by using SPSS statistical software. Most favorable Linear and nonlinear correlations were investigated. By investigating proposed correlations in studied field and their comparison, the following results were obtained:

1. In the comparison of proposed linear correlations, linear correlation without intercept with statistical test of 383/946, correlation coefficient of 0.904 and coefficients of determination 0.818 superior and more reliable than linear correlation with intercept, with the statistical test of $344 / 567$, correlation coefficient of 0.0 .788 and coefficients of determination 0.62 is determined.

2. In the comparison of nonlinear correlations, nonlinear correlation with a coefficient of determination 0.775, two proposed non-linear correlations when use mud pumps in the well, determined coefficients are 0.819 and 0.813 . The

\begin{tabular}{|c|c|c|c|c|c|c|}
\hline Sig & $\mathbf{t}$ & parameter & $\mathbf{F}$ & R2 & $\mathbf{R}$ & Proposed equation \\
\hline 0 & -20.355 & ROP & \multirow{8}{*}{344.568} & \multirow{8}{*}{0.62} & \multirow{8}{*}{0.788} & \multirow{8}{*}{$\begin{array}{c}M S E=-3.153 \text { Driiled-27.947ROP+3.487N+14.547WOB }+0.649 \\
\Delta P+38.201 T Q+0.165 Q-646.282\end{array}$} \\
\hline 0 & 8.584 & $\mathrm{~N}$ & & & & \\
\hline 0 & 11.611 & WOB & & & & \\
\hline 0.298 & 1.04 & $Q$ & & & & \\
\hline 0 & 5.27 & $\Delta \mathrm{P}$ & & & & \\
\hline 0 & 21.21 & $\mathrm{TQ}$ & & & & \\
\hline 0.001 & -3.343 & Drilled & & & & \\
\hline 0 & -4.595 & Constant & & & & \\
\hline
\end{tabular}
proposed nonlinear correlation when use mud pumps in the

Table 5: Linear correlation with intercept between the mechanical specific energy and other drilling parameters. 
well correlation coefficients obtained 0.837 and 0.832 , which compared to the other proposed non-linear correlation are above. This represents a further connection between the parameters and higher accuracy of mechanical specific energy correlation with other independent parameters of drilling in the correlation.

Of the seven suggested correlations for the studied area, linear correlation without intercept:

$(\mathrm{MSE}=-28.120 \times \mathrm{ROP}+3.287 \times \mathrm{N}+14.083 \times \mathrm{WOB}-0.511 \times \mathrm{Q}+$ $0.532 \times \Delta \mathrm{P}-37.89 \times \mathrm{TQ}-2.747 \times$ Drilled $)$

There is a slight difference in coefficient of determination than some of the non-linear correlation (linear correlation of superiority toward non-linear correlation) is considered to be the most appropriate correlation. To obtain the most influential independent parameters on mechanical specific energy and " $t$ " the correlation is investigated. As a result, the most effective independent parameters depend on parameters such as torque, bit penetration rate, weight on bit, mud flow rate, rotational speed, pressure difference and measure depth of drilling. So, more suitable optimization of mechanical specific energy, for drilling other rigs in this region (in the formations such as Hith, Surmeh, Neyriz, Dashtak and Kangan) is recommended. Drilling parameters (with priority influencing on mechanical specific energy), that are ranged in the proposed optimum limit.

It should be noted that between these parameters, weight on bit, mud flow rate and rotational speed on rig can be controlled by drillers. Torque and pressure difference cannot be controlled independently (rotational speed and torque directly related to the pressure difference between a direct relationship with the mud flow rate). Also by changes on three parameters such as weight of bit, mud flow rate and rotational speed, can be also changed in the formation of bit penetration rate.

\section{Results and Discussion}

Suggested optimization of drilling parameters, for 12.25 inch sections for each geological formations described as below:

A) Hith Formation include rotational velocity from 30 to 120 with an average of 66.85 (RPM), weight on bit from 3 to 25 with an average of 17.55 (klbs), flow rate of 795 to 910 with an average score of 840.77 (gal / min), the pressure difference of 110 to 340 with an average of 243.33 (psi) and torque from 0 to 18 with an average of 20.22 (kFT-lb).

B) Surmeh Formation include rotational velocity from 0 to 120 with an average of 77.5 (RPM), weight on bit from 0 to 80 with an average of 15.75 (klbs), flow rate of 795 to 950 with an average score of 869.7 ( $\mathrm{gal} / \mathrm{min}$ ), the pressure difference of 40 to 445 with an average of 195.33 (psi) and torque from 0 to 25 with an average of 7.43 (kFT-lb).

C) Neyriz Formation include rotational velocity from 60 to 120 with an average of 111 (RPM), weight on bit from 4 to 25 with an average of 13.65 (klbs), flow rate of 750 to 950 with an average score of 869.7 (gal / $\mathrm{min}$ ), the pressure difference of 130 to 350 with an average of 248.5 (psi) and torque from 5 to 26 with an average of 14.15 (kFT-lb).

D) Dashtak Formation include rotational velocity from 0 to 120 with an average of 81.5 (RPM), weight on bit from 1 to 30 with an average of 13.63 (klbs), flow rate of 200 to 950 with an average score of 808.36 ( $\mathrm{gal} / \mathrm{min}$ ), the pressure difference of 10 to 370 with an average of 163.9 (psi) and torque from 0 to 26 with an average of 13.63 (kFT-lb).

E) Kangan formation include rotational velocity from 105 to 120 with an average of 114.33 (RPM), weight on bit from 18 to 33 with an average of 25.7 (klbs), flow rate of 800 to 900 with an average score of
854.2 (gal / $\mathrm{min}$ ), the pressure difference of 80 to 335 with an average of 157 (psi) and torque from 9 to 29 with an average of 17.5 (kFT-lb).

\section{Conclusion}

Since the bit penetration rates compared to the control parameters (weight on bit, mud flow rate and rotational speed) is more effective on mechanical specific energy, changing three parameters aimed at accelerating drilling speed was more important than exposure these parameters are proposed in the optimum range.

To use the results of this research should be considered within these parameters to provide the specification describes, in normal curve and histogram drilling parameters. As well as from a variety of statistical methods, SPSS software was used in this research.

As noted above, the mechanical specific energy can check mechanical drilling performance (selected and optimized drilling parameters), check the performance of bit (design bit more efficiently) and help to the failure of drilling. However, we don't have appropriate processing statistical method for optimizing drilling parameters and their effect on mechanical specific energy in the studied area has not done and whereas mechanical specific energy has an important role in reduction of costs in this research by using mechanical specific energy in analyzing and optimizing drilling parameters in part of Iran south pars field. So it is recommended by using mechanical specific energy for investigating drilling instabilities (which can include bit plunge and BHA in the mud, vibrations, improper cleaning of wells, etc.) and check the performance of the bit in the area to be addressed. By selecting the appropriate type of bit (fixed cutter, PCD, etc.), appropriately designed bit (number of blades, size and density of cutters, side angle Rick and, number and size of nozzles) and taking cutting depth adjacent pressure etc., must be increased drilling speed and minimize damage to the bit.

\section{References}

1. Amadi WK, lyalla I (2012) Application of mechanical specific energy techniques in reducing drilling cost in deepwater development. Paper SPE 156370-MS presented at the SPE Deepwater Drilling and Completion Conference held in Galveston, Texas, USA.

2. Azike-Akubue V, Barton S, Gee R, Burnett T (2012) SPE, National Oilwell Varco. Aglitation tools enable significant reduction in mechanical specific energy. Paper SPE 158240-MS presented at the SPE Asia Pacific Oil and Gas Conference and Exhibition held in Perth, Australia.

3. Bradford J, Ferrari LA, Rickabaugh C, Rothe M, Tipton B (2012) Hybrid drill bit combining fixed-cutter and roller-cone elements improves drilling performance in Marcellus shale surface interval. Paper SPE 154831 presented at the Americas Unconventional Resources Conference held in Pennsylvania, USA.

4. Caicedo H, Calhoun W, Ewy R (2005) Unique ROP predictor using bitspecific coefficient of sliding friction and mechanical efficiency as a function of confined compressive strength impacts drilling performance. paper SPE 92576 presented at 2005 SPE Drilling Conference, Amsterdam, The Netherlands.

5. Dupriest FE, Mobil E, L Koederitz W (2005) Maximizing drill rates with real-time surveillance of mechanical specific energy. Paper SPE/IADC 92194 presented at the SPE/IADC Drilling Conference held in Amsterdam, The Netherlands.

6. Hammoutene C, Bits S (2012) FEA modelled MSE/UCS values optimise PDC design for entire hole section, Paper SPE 149372 presented at the North Africa Technical Conference and Exhibition held in Cario, Egypt.

7. Kim SY (2008) Comparison of the decision tree, artificial neural network, and linear regression method based on the number and types of independent variables and sample size. Expert system with application 34: 1227-1234.

8. Mensa-Wilmot G, James B, Bits S, Aggarwal L, Van Luu H, et al. (2006) Gage design-effects of gage pad length, geometry, and activity (side cutting) on PDC bit stability, steer ability, and borehole quality in rotary steerable. Paper IADC/ SPE 98931 presented at the IADC/SPE Drilling conference held in Miami, Florida, USA. 
Citation: Davarpanah A, Zarei M, Mehdi-Nassabeh SM (2016) Assessment of Mechanical Specific Energy Aimed at Improving Drilling Inefficiencies and Minimize Wellbore Instability. J Pet Environ Biotechnol 7: 309. doi: 10.4172/2157-7463.1000309

Page 6 of 6

9. Mohan K, Adil F, Halliburton SR (2009) Tracking drilling efficiency using hydromechanical specific energy. Paper SPE/IADC 119421 presented at the SPE/ IADC Drilling Conference and Exhibition held in Amsterdam, The Netherlands.

10. NIST (2010) Structural robustness large-scale testing.

11. Rajabov V, Miska S (2012) The effects of back-rake and side-rake angles on mechanical specific energy of single PDC cutters with selected rocks at varying depth of cuts and confining pressures. Paper IADC/SPE 151406 presented at the IADC/SPE Drilling Conference and Exhibition held in San Diego, California, USA.

12. Remmert SM, Witt JW, Dupriest FE (2007) SPE, Implementation of ROP management process in Qatar North field. Paper SPE/IADC 105521 presented at the 2007 Drilling Conference held in Amsterdam, The Netherlands.

13. Guerrero C (2007) SPE Drilling Studies Group, Drilling Engineer, Drilling Solutions Team. Drilling Optimization with Mechanical Specific Energy.

14. Waughman R, Kenner J, Moore R (2002) Real-time specific energy monitoring reveals drilling inefficiency and enhances the understanding of when to pull worn PDC bits. Paper SPE 74520 presented at 2002 SPE Drilling Conference Dallas, Texas.

15. MSE (2010) A valuable trending tool for drillers and engineers. 